\title{
Asesmen perilaku fungsional pada perilaku menyakiti diri sendiri anak autis di SLB Autisma Dian Amanah Yogyakarta
}

\author{
Dhea Ellyne Theodora ${ }^{1}$, Aini Mahabbati ${ }^{2}$ \\ ${ }^{1}$ Jurusan Pendidikan Luar Biasa, Universitas Negeri Yogyakarta. \\ ${ }^{2}$ Jurusan Pendidikan Luar Biasa, Universitas Negeri Yogyakarta. \\ * Corresponding Author. E-mail: dheaellyne@gmail.com
}

\begin{abstract}
Abstrak: Penelitian ini bertujuan untuk mendeskripsikan perilaku menyakiti diri pada anak autis di SLB Autisma Dian Amanah Yogyakarta menggunakan prosedur asesmen perilaku fungsional. Penelitian difokuskan pada setting perilaku di sekolah, dengan pengumpulan data berupa antecedent, behavior, consequence, dan faktor mempengaruhi. Penelitian ini merupakan penelitian kualitatif eksploratori. Subjek penelitian meliputi 2 siswa autis yaitu NKW dan AGS. Teknik pengumpulan data menggunakan observasi, wawancara, dan pengisian skala motivasi perilaku. Data dianalisis menggunakan deskriptif kualitatif yaitu dengan menyajikan data dalam bentuk naratif dan tabel. Hasil penelitian menunjukkan antecedent munculnya perilaku menyakiti diri berupa efek interaksi tidak menyenangkan, kebisingan verbal, kegiatan tidak disukai, cuaca panas, melihat benda tidak sesuai tempat, dan melihat objek ditakuti. Consequence perilaku berupa mendapat sensasi menyenangkan pada indera (sensory), terhindar dari tugas atau kegiatan (escape), maupun mendapat perhatian (attention). Faktor yang dapat mempengaruhi perilaku berupa kemampuan komunikasi ekspresi yang rendah, pengkonsumsian obat-obatan, pola tidur tidak teratur, serta level autismenya.
\end{abstract}

Kata Kunci: Menyakiti Diri, Anak Autis, Asesmen Perilaku Fungsional

\section{Functional behavior assessment for self injurious behavior of autistic children in SLB Autisma Dian Amanah Yogyakarta}

\begin{abstract}
The purpose of this research is to describe self injurious behavior in autistic children SLB Autisma Dian Amanah Yogyakarta using Functional Behavior Assessment. The research focused on behavioral settings in schools, with data collection is antecedent, behavior, consequence, and factors that influence. This research is a qualitative exploratory study. The research subjects included 2 autism student, which is NKW and AGS. Data collection techniques use observation, interviews, and filling motivation assessment scale. The data analysis use qualitative descriptive that showed the narrative and table. The results of this research showed the antecedent self injurious behaviors is unpleasant interaction effects, verbal noise, disliked activities, hot weather, seeing objects that are not in place, and seeing feared objects. The consequence behavior is getting a pleasant sensation (sensory), avoiding tasks/activities (escape), and getting attention. The factors that influence behavior is low expression communication skills, consumption medicines, less regular sleep patterns, and the level of autism.
\end{abstract}

Keywords: Self Injurious Behavior, Autistic Child, Functional Behavior Assessment

\section{PENDAHULUAN (10\%)}

Autis merupakan salah satu tipe kebutuhan khusus. Autis merupakan gangguan perkembangan yang dapat mempengaruhi beberapa aspek dalam kehidupan penyandangnya. Berdasarkan DSM-V (American Psychiatric Association, 2013: 50) anak autis memiliki 2 ciri utama yang menjadi kekhasannya yaitu adanya gangguan pada aspek komunikasi-interaksi sosial dan perilaku. Pada aspek komunikasi-interaksi sosial, anak autis memiliki hambatan dalam membangun hubungan komunikasi interaksi dengan orang lain. Adapun pada aspek perilaku, beberapa bentuk perilaku anak autis menunjukkan perbedaan yang mencolok dibandingkan dengan anak-anak pada umumnya.

Sastry \& Aguirre (2014: 16) menuliskan bahwa anak autis bisa memiliki perilaku yang berkekurangan (deficit) atau perilaku yang berlebihan (excessive). Bentuk lain perilaku bermasalah pada anak autis adalah perilaku yang repetitif dan stereotip (Hallahan, Kauffman \& Pullen, 2009: 425). 
Perilaku repetitif dan stereotip merupakan perilaku yang dilakukan secara berulang dan sering tanpa ada kejelasan motif. Bentuk perilaku repetitif dan stereotip yaitu mengetuk-ngetukan jari (tapping), mengepak-ngepakkan tangan (hand flapping), memukul-mukul kepala (menyakiti diri), dan lain-lain.

Terdapat salah satu perilaku yang menarik untuk dikaji yaitu perilaku menyakiti diri pada anak autis. Minshawi, Hurwitz, Fodstad, Biebl, Morris, McDoughle (2014: 126) menuliskan bahwa menyakiti diri merupakan sebuah perilaku yang sengaja dilakukan individu itu sendiri untuk mengakibatkan cedera fisik. Perilaku menyakiti diri pada anak autis berbeda dengan orang gangguan kejiwaan. Perilaku menyakiti diri pada anak autis diklasifikasikan pada perilaku menyakiti diri stereotip, berbeda dengan menyakiti diri yang dilakukan dengan sengaja untuk percobaan bunuh diri, dimana perilaku tersebut biasa terjadi pada individu dengan gangguan kejiwaan tingkat berat dan bentuk perilakunya berupa mutilasi, menggunting anggota tubuh, menggantung, dan lain-lain. Anak autis melakukan perilaku menyakiti diri untuk mendapatkan luka atau rasa sakit sebagai ungkapan atau ekspresi perasaan yang tidak menyenangkan. Beberapa bentuk perilaku menyakiti diri pada anak autis, yaitu memukul, menjambak rambut, menggigit, membenturkan kepala.

Pra penelitian pada bulan November 2018, menemukan kasus menyakiti diri pada anak autis di SLB Autisma Dian Amanah Yogyakarta. Perilaku menyakiti diri yang ditemukan berupa memukul kepala menggunakan tangan. Terdapat 2 siswa autis yang memiliki perilaku bermasalah menyakiti diri. Siswa tersebut adalah NKW kelas 4 SDLB berusia 12 tahun dan AGS kelas 8 SMPLB berusia 16 tahun.

Kedua siswa dengan perilaku bermasalah menyakiti diri ini melakukan perilaku menyakiti diri setiap hari. Terdapat bentuk perilaku menyakiti diri yang sama pada kedua siswa tersebut yaitu memukul kepala menggunakan tangan. Namun, perilaku menyakiti diri tersebut memiliki setting event dan menghasilkan dampak yang berbeda. Sejauh ini, pihak sekolah belum melaksanakan asesmen perilaku bermasalah untuk kedua siswa. Belum adanya pelaksanaan asesmen perilaku bermasalah ini, menyebabkan guru kelas kurang memahami mengenai pemicu, faktor penyebab dan sesuatu yang ingin dikomunikasikan oleh anak melalui perilaku bermasalah yang muncul. Sehingga, peneliti tertarik untuk mendalami dan melakukan penelitian mengenai perilaku menyakiti diri pada kedua siswa autis tersebut untuk menemukan pemicu, bentuk perilaku yang muncul, konsekuensi, serta faktor penyebab perilaku bermasalah terjadi.

Intervensi yang dilakukan oleh guru kelas sejauh ini berupa guru mengingatkan anak dengan kata "tangannya”, “stop”, dan "tidak”. Namun biasanya subjek tetap memukul-mukulkan kepala. Saat guru memegang kedua tangan subjek dan menguncinya, subjek sering melawan dan tetap memukul pada bagian tubuh apa saja yang terkena. Bila tangan subjek sudah tidak dapat bergerak, maka hal yang subjek lakukan adalah melampiaskan pada benda di sekitarnya seperti kaki menendang pada lantai, mendendang meja, membuang benda dan lain lain.

Perilaku menyakiti diri memukul kepala pada anak autis harus dihentikan karena akan berdampak buruk pada anak, seperti cedera, mempengaruhi fungsi otak, lumpuh, maupun menggangu lingkungan sekitar. Sehingga, perlu dilakukan penelitian untuk dapat memahami pola perilaku menyakiti diri pada kedua subjek penelitian guna analisis data untuk pembuatan rancangan intervensi dini. Sebagai dasar penyusunan rancangan intervensi bagi anak, asesmen perilaku bermasalah perlu dilakukan terlebih dahulu.

Salah satu pendekatan asesmen perilaku yang dapat digunakan untuk memahami karakteristik perilaku bermasalah adalah Functional Behavior Assessment atau Asesmen Perilaku Fungsional. Asesmen Perilaku Fungsional menurut Minshawi,dkk (2014: 129) merupakan metode asesmen untuk mengembangkan intervensi perilaku yang dapat mempertahankan efektivitasnya setiap waktu. Asesmen Perilaku Fungsional memberikan hipotesis tentang hubungan di antara jenis-jenis peristiwa dan tingkah laku tertentu yang terjadi di lingkungan. Secara spesifik, Asesmen Perilaku Fungsional dirancang untuk mendapatkan informasi tentang fungsi atau motif sebuah tingkah laku seseorang. Seluruh informasi dari hasil asesmen perilaku menggunakan Asesmen Perilaku Fungsional selanjutnya dapat digunakan untuk merancang intervensi yang dapat mengurangi masalah perilaku dan atau meningkatkan perilaku yang positif.

\section{METODE PENELITIAN}

Pendekatan yang digunakan dalam penelitian ini yaitu pendekatan kualitatif eksploratori. Penelitian eksploratori menurut Mudjiyanto (2018: 65) adalah penelitian yang bertujuan memperdalam 


\section{J PK (J urnal Pendidikan Khusus), 15 (1), 2019 - 60}

Dhea Ellyne Theodora, Aini Mahabbati

pengetahuan dan mencari ide-ide baru mengenai suatu gejala tertentu, menggambarkan fenomena sosial, dan menjelaskan bagaimana terjadinya suatu fenomena sosial untuk merumuskan masalah secara lebih terperinci atau mengembangkan hipotesis bukan menguji hipotesis. Informasi-informasi yang diperoleh dalam penelitian, disusun dengan uraian catatan, direduksi, dirangkum, dan dipilih informasi yang sesuai dengan tujuan penelitian, yang selanjutnya dianalisis secara deskriptif kualitatif. Penelitian ini bertujuan untuk mengkaji lebih mendalam dan mengidentifikasi mengenai pola perilaku menyakiti diri pada anak autis di SLB Autisma Dian Amanah Yogyakarta berdasarkan prosedur asesmen perilaku fungsional.

\section{Waktu dan Tempat Penelitian}

Penelitian ini dilaksanakan selama 2 bulan pada bulan Februari hingga April 2019. Penelitian berlokasi di SLB Autisma Dian Amanah Yogyakarta beralamat di Jalan Sawah Joglo, Sinduharjo, Ngaglik, Sleman, DIY.

\section{Subjek Penelitian}

Subjek yang digunakan dalam penelitian adalah 2 orang siswa autis yang memiliki perilaku bermasalah berupa menyakiti diri. Subjek tersebut terdiri dari NKW berusia 12 tahun kelas 4 SDLB dan AGS berusia 16 tahun kelas 8 SMPLB.

\section{Teknik Pengumpulan Data}

Teknik pengumpulan data yang digunakan berupa observasi, wawancara, dokumentasi, dan pengisian skala. Instrumen dalam penelitian ini disusun berdasarkan prosedur asesmen perilaku fungsional (Shippen, Simpson \& Crites (2003: 37); Hadaway \& Brue (2016:17); Thomas \& William dalam Autism Society of North Carolina (2019)).

1. Teknik Observasi

Jenis observasi yang digunakan adalah observasi non partisipan, yaitu pengamatan dilakukan secara langsung dan peneliti hanya datang sebagai pengamat di tempat penelitian tanpa melibatkan diri dalam kegiatan subjek. Observasi dilakukan untuk menggali data mengenai pola perilaku menyakiti diri pada kedua subjek dan melakukan pencatatan perilaku menyakiti diri yang muncul saat di sekolah selama 3 hari pada masing-masing subjek, dihitung mulai pukul 07.30 - 14.00 WIB. Peneliti menggunakan kamera diletakkan tersembunyi untuk membantu merekam kegiatan dan perilaku siswa.

Instrumen pelaksanaan observasi berisi pencatatan bentuk-bentuk perilaku menyakiti diri, antecedent, consequence, dan faktor yang mempengaruhi munculnya perilaku menyakiti diri. Peneliti juga melakukan pencatatan perilaku pada saat penelitian. Pencatatan perilaku yang digunakan adalah continuous recording, dengan pencatatan berupa frekuensi dan intensitas munculnya perilaku masingmasing subjek. Form pencatatan perilaku yang digunakan dalam penelitian ini merupakan adaptasi dari Miltenberger (2009) yang diterjemahkan. Pencatatan frekuensi dilakukan dengan menulis tally atau turus setiap perilaku yang ditargetkan muncul dan pencatatan intensitas (secara deskriptif dengan menuliskan berat, sedang, atau ringan).

Peneliti menggunakan triangulasi penyidik untuk melakukan pencatatan perilaku. Peneliti menggunakan dua observer yaitu peneliti sendiri, dan terdapat 1 observer lain agar hasil pengamatan lebih terpercaya. Miltenberger (2009: 33) menyebut interobserver agreement (IOA) yang bermakna terdapat dua orang yang melakukan pengamatan dan pencatatan pada perilaku target yang sama dan dalam periode waktu yang sama. Selanjutnya hasil pencatatan kedua observer dibandingkan dan dihitung persentasenya. Adapun penghitungan persentasenya adalah:

$$
I O A=\frac{\text { jumlah frekuensi rendah }}{\text { jumlah frekuensi tinggi }} \times 100 \%
$$

Pada sebuah penelitian, hasil persentase IOA minimal yang diterima adalah $80 \%$, jika lebih akan menjadi lebih baik. Hal ini menunjukkan bahwa pencatatan perilaku target dilakukan secara asli dan terbukti objektif.

\section{Teknik Wawancara}

Pertanyaan wawancara bersifat terbuka agar mendapatkan informasi sebanyak-banyaknya. Wawancara ditujukan kepada guru kelas subjek, guru sekolah selain guru kelas, dan orang tua subjek. Wawancara dilakukan untuk menggali data mengenai bentuk perilaku, dugaan pemicu, dampak dan respon lingkungan, serta faktor yang mempengaruhi perilaku muncul.

3. Teknik Pengisian Skala

Skala yang digunakan dalam penelitian ini adalah skala likert. Sugiyono (2017: 104) berpendapat bahwa skala likert digunakan untuk mengukur sikap, pendapat, dan persepsi seseorang 
atau sekelompok orang tentang fenomena sosial. Peneliti menggunakan skala untuk mengukur motif perilaku guna mengetahui motif perilaku menyakiti diri pada subjek. Peneliti menggunakan skala motivasi perilaku (Motivation Assessment Scale) dari Durand \& Crimmins (1986) yang diterjemahkan.

\section{Teknik Analisis Data}

Model analisis data yang digunakan dalam penelitian ini adalah analisis kualitatif model Miles dan Huberman. Miles \& Huberman (1992: 15-20) mengungkapkan bahwa analisis data penelitian kualitatif dapat dilakukan melalui langkah-langkah berupa reduksi data, penyajian data, dan menarik kesimpulan.

\section{Reduksi Data}

Reduksi data merupakan suatu bentuk analisis yang menajamkan, menggolongkan, mengarahkan, membuang yang tidak perlu, dan mengorganisasi data dengan cara sedemikian rupa hingga kesimpulan-kesimpulan akhir dapat ditarik dan diverifikasi. Hasil observasi dan wawancara yang didapatkan selanjutnya peneliti reduksi untuk menyusun informasi yang penting dan digunakan dalam penarikan kesimpulan.

\section{Penyajian Data}

Penyajian data yang dapat digunakan dalam penelitian kualitatif adalah teks naratif penyajian yang paling sering digunakan, berbagai jenis matriks, grafik, tabel, dan bagan. Semua dirancang guna menggabungkan informasi yang tersusun dalam suatu bentuk yang padu dan mudah diraih. Dalam penelitian ini, peneliti akan menyajikan data dalam bentuk teks naratif dan tabel.

3. Menarik Kesimpulan/verifikasi

Melakukan penarikan kesimpulan dalam pengumpulan data, hal yang harus dilakukan adalah peneliti harus mengerti dan tanggap terhadap sesuatu yang diteliti langsung di lapangan dengan menyusun pola-pola pengarahan dan sebab akibat. Setelah hasil penelitian telah diuji kebenarannya, maka peneliti dapat menarik kesimpulan dalam bentuk deskriptif sebagai laporan penelitian. Kesimpulan ditarik berdasarkan hasil analisis asesmen perilaku bermasalah menggunakan asesmen perilaku fungsional tentang pola perilaku menyakiti diri pada anak autis.

\section{HASIL DAN PEMBAHASAN}

\section{Hasil penelitian}

1. Deskripsi Perilaku Menyakiti Diri

a. Bentuk Perilaku Menyakiti Diri

Terdapat beberapa macam bentuk perilaku menyakiti diri yang dilakukan oleh NKW, yaitu memukul kepala dengan tangan dimana perilaku ini merupakan perilaku yang sangat sering muncul dengan frekuensi rata-rata 28-29 kali/jam dan intensitas ringan. Selain itu terdapat perilaku menyakiti diri lainnya yaitu dengan membenturkan kepala pada meja frekuensi rata-rata 0,67-0,7 kali/jam dan intensitas sedang, membenturkan kaki pada lantai dengan frekuensi rata-rata 3,2-3,3 kali/jam dan intensitas ringan, dan menyayat kulit di sekitar kuku jari tangan.

Bentuk perilaku menyakiti diri yang sering sekali dilakukan oleh AGS adalah memukul kepala menggunakan tangan dengan frekuensi rata-rata 4,4-4,7 kali/ jam dan intensitas yang berat. Bentukbentuk perilaku menyakiti diri yang lain yang dapat dilakukan AGS adalah perilaku memukul meja (gebrakan pada meja) dengan frekuensi rata-rata 1 kali/jam dan intensitas yang berat. AGS memiliki energy dan tenaga yang kuat sehingga setiap kali melakukan perilaku apapun selalu dilakukannya dengan keras termasuk perilaku menyakiti diri.

b. Antecedent Perilaku Menyakiti Diri

Berdasarkan hasil observasi dan hasil wawancara yang telah dilakukan peneliti, bahwa anteseden perilaku menyakiti diri pada NKW sering terjadi saat bersama guru kelas. Kondisi lingkungan yang dapat memicu adalah saat mendapat interaksi yang tidak menyenangkan, kebisingan verbal, kegiatan pembelajaran mengenal konsep, kegiatan apel motivasi, melihat benda tidak sesuai pada tempatnya, melihat objek yang ditakuti, cuaca yang panas, diganggu oleh orang lain, dan penundaan atau pembatalan suatu kegiatan yang sudah menjadi rutinitasnya.

Anteseden perilaku menyakiti diri pada AGS adalah perilaku menyakiti diri pada AGS sering terjadi saat bersama guru kelas. Kondisi lingkungan yang dapat memicu adalah adanya kebisingan verbal, melakukan maupun mendengar pembelajaran mengenal konsep, saat melihat makanan di dalam kotak makan, dan saat AGS diberikan instruksi namun ia menolak. 


\section{c. Consequences Perilaku Menyakiti Diri}

Dampak secara langsung pada NKW dari perilaku memukul kepala adalah berupa kemerahan dan muncul benjolan kecil pada bagian dahi yang terkena pukulan. Dampak tersebut memiliki dampak jangka panjang yaitu berupa menyebabkan kulit menjadi menghitam pada bagian dahi yang sering terkena pukulan dan benturan pada meja. Dampak perilaku menyayat kulit di sekitar kuku jari tangan adalah menyebabkan luka sayatan kulit pada daerah sekitar kuku jari tangan. Respon lingkungan akibat perilaku menyakiti diri pada NKW adalah membuat siswa lain yang masih kecil menjadi sedikit takut menyaksikan NKW memukul kepala. Melalui wawancara, diketahui bahwa lingkungan tidak terlalu mendapat dampak buruk akibat perilaku menyakiti diri yang dilakukan NKW.

Dampak secara langsung perilaku menyakiti diri memukul kepala pada AGS berupa timbulnya kemerahan pada kulit kepala bagian yang terkena pukulan sangat keras dan muncul sedikit benjolan jika diraba. Dampak jangka panjang bagi AGS yaitu tidak tumbuhnya rambut atau bothak pada bagian kepala yang sering terkena pukulan. Selanjutnya dampak lingkungan akibat perilaku menyakiti diri AGS adalah suasana lingkungan sekitar menjadi tidak kondusif akibat orang di lingkungan sekitar mengalihkan perhatiannya pada perilaku menyakiti diri AGS dan mencoba untuk mengehentikan perilaku tersebut, serta membuat perasaan takut, cemas, dan khawatir bagi orang yang berada di sekitar AGS.

d. Faktor Mempengaruhi Perilaku

Kedua subjek memiliki hasil yang sama, yaitu hasil kemampuan komunikasi reseptif pada kedua subjek sudah tergolong baik meskipun memiliki tingkat kemampuan masing-masing, kemampuan komunikasi ekspresif kedua subjek sama yaitu masih tergolong rendah, dan kejelasan instruksi kedua guru kelas subjek sama yaitu sudah sangat jelas karena menggunakan metode step by step.

2. Motivasi Perilaku Bermasalah

Motivasi perilaku bermasalah yang paling dominan pada kedua subjek adalah sensory (mendapatkan rasa menyenangkan pada indera), escape (menghindari tugas/kegiatan), attention (mendapatkan perhatian).

Tabel 1. Motif Perilaku Subjek NKW

\begin{tabular}{lcccc}
\hline Perilaku Menyakiti Diri & Motivasi 1 & Skor 1 & Motivasi 2 & Skor 2 \\
\hline Memukul kepala & Sensory & 14 & Escape & 10 \\
Membenturkan kepala pada meja & Escape & 18 & Tangible & 11 \\
Membenturkan kaki pada lantai & Attention & 13 & Sensory & 12 \\
Menyayat kulit jari & Sensory & 15 & Attention & 11 \\
\hline
\end{tabular}

Tabel 2. Motif Perilaku Subjek AGS

\begin{tabular}{lcccc}
\hline Perilaku Menyakiti Diri & Motivasi 1 & Skor 1 & Motivasi 2 & Skor 2 \\
\hline Memukul kepala & Escape & 16 & Sensory & 14 \\
Menggebrak meja & Attention & 18 & Sensory & 15 \\
\hline
\end{tabular}

\section{Analisa Pola Perilaku}

Pola perilaku disimpulkan dari pengamatan berulang yang dilakukan selama 3 hari berturutturut pada setting di lingkungan sekolah. Hasil analisa didapatkan dari hasil deskripsi penelitian pada perilaku bermasalah (behavior), pemicu munculnya perilaku bermasalah (antecendent), dan hal yang terjadi atau konsekuensi setelah munculnya perilaku bermasalah (consequences). Adapun analisa pola ABC yang didapatkan adalah sebagai berikut :

Tabel 3. Analisa Pola Perilaku NKW

\begin{tabular}{lll}
\hline \multicolumn{1}{c}{ Antecedents } & \multicolumn{1}{c}{ Behavior } & Consequences \\
\hline - Efek interaksi tidak & - Memukul kepala menggunakan & - Dampak yang muncul: \\
menyenangkan dari orang lain. & tangan & - Sedikit memerah \\
- Kebisingan verbal. & - Membenturkan kepala pada & - Dahi menjadi sedikit berwarna \\
- Kegiatan pembelajaran mengenal & meja & hitam. \\
konsep. & - Membenturkan kaki pada lantai & - Terdapat luka di sekitar kuku jari \\
- Diberikan tugas sulit. & - Menyayat kulit di sekitar kuku & tangan \\
- Terpapar panas terik matahari di & jari tangan & - Respon guru: pemberian instruksi \\
\hline
\end{tabular}




\begin{tabular}{|c|c|c|}
\hline Antecedents & Behavior & Consequences \\
\hline $\begin{array}{l}\text { luar ruangan. } \\
\text { - Udara yang panas. } \\
\text { - Melihat benda tidak sesuai pada } \\
\text { tempatnya } \\
\text { - Melihat objek yang ditakuti. } \\
\text { - Penundaan dan pembatalan suatu } \\
\text { rutinitas. } \\
\text { - Guru menyatakan anak salah } \\
\text { (dalam menjawab pertanyaan } \\
\text { atau melakukan tugas). }\end{array}$ & & $\begin{array}{l}\text { verbal untuk menghentikan } \\
\text { perilaku. } \\
\text { - Respon teman: beberapa siswa } \\
\text { kecil tampak ketakutan. } \\
\text { - Mendapatkan rasa sensasi } \\
\text { menyenangkan pada indera } \\
\text { (sensory). } \\
\text { - Terhindar dari sebuah tugas } \\
\text { maupun kegiatan. }\end{array}$ \\
\hline
\end{tabular}

Tabel 4. Analisa Pola Perilaku AGS

\begin{tabular}{lll}
\hline \multicolumn{1}{c}{ Antecedents } & \multicolumn{1}{c}{ Behavior } & \multicolumn{1}{c}{ Consequences } \\
\hline Kebisingan verbal. & Memukul kepala & Dampak yang muncul: \\
Melakukan pembelajaran mengenal konsep. & menggunakan tangan & Lebam \\
$\begin{array}{l}\text { Mendengar teman belajar mengenal konsep. } \\
\text { Melihat makanan diletakkan di kotak makan. }\end{array}$ & $\begin{array}{l}\text { Memukul meja dengan tangan } \\
\text { (menggebrak) }\end{array}$ & $\begin{array}{l}\text { Muncul benjol } \\
\text { Diberikan instruksi namun anak menolak. }\end{array}$ \\
& & Bothak \\
& & $\begin{array}{l}\text { Respon guru: pemberian instruksi verbal } \\
\text { untuk menghentikan perilaku. }\end{array}$ \\
& & Respon teman: siswa kecil tampak \\
& & ketakutan, guru dan lingkungan sekitar \\
& & tampak cemas serta khawatir. \\
& & Terhindar dari tugas maupun kegiatan. \\
& & Mendapatkan perhatian dari orang lain. \\
\hline
\end{tabular}

\section{Pembahasan}

Berdasarkan hasil penelitian, maka diketahui bahwa subjek dengan inisial NKW dan AGS merupakan seorang siswa autis yang memiliki perilaku bermasalah berupa perilaku menyakiti diri.

1. Bentuk Perilaku Menyakiti Diri

Terdapat salah satu bentuk perilaku menyakiti diri yang sama yaitu memukul kepala menggunakan tangan. Perilaku menyakiti diri subjek penelitian sesuai dengan teori Yates dalam Minshawi (2014: 125-136) bahwa perilaku menyakiti diri pada anak autis dikategorikan pada perilaku menyakiti diri yang berpola stereotip, bukan perilaku menyakiti diri yang berhubungan dengan penyakit kejiwaan. Perilaku NKW dan AGS merupakan perilaku menyakiti diri yang stereotip karena perilaku tersebut dilakukan secara berulang dan dilakukan setiap harinya sebagai bentuk pengungkapan perasaan yang tidak disukainya, bukan dilakukan dengan sengaja untuk bunuh diri.

2. Pengaruh Level Autis

Menurut Minshawi, dan kawan-kawan (2014: 52) bentuk perilaku menyakiti diri pada anak autis semakin berat dipengaruhi oleh salah satunya level berat ringan autismenya. Semakin berat gejala autismenya, maka semakin beresiko pula perilaku menyakiti dirinya, memiliki frekuensi yang tinggi dan bentuk perilakunya pun biasanya semakin membahayakan atau berat. Kedua subjek penelitian memiliki level autis yang berbeda, NKW tergolong pada autis sedang, sedang AGS tergolong pada autis berat. Perilaku menyakiti diri NKW sangat sering terjadi namun tidak dengan intensitas yang berat. Berbeda dengan bentuk perilaku menyakiti diri AGS yaitu tidak sering terjadi namun saat perilaku terjadi muncul dengan intensitas yang sangat berat. Teori Minshawi, dan kawankawan (2014: 52) terbukti jelas karena AGS memiliki level autis lebih berat dan memiliki bentuk perilaku menyakiti diri yang lebih berat pula dibanding NKW.

3. Faktor yang Mempengaruhi Perilaku Menyakiti Diri

Faktor yang mempengaruhi munculnya perilaku menyakiti diri pada kedua subjek penelitian sejalan dengan teori Richards, Davies, \& Oliver (2017: 37). Perilaku menyakiti diri pada subjek penelitian dipengaruhi oleh beberapa hal yaitu:

a. Memiliki komunikasi rendah, akademik rendah, dan lain-lain.

Kedua subjek penelitian memiliki kemampuan komunikasi yang masih tergolong rendah, terutama kemampuan komunikasi ekspresif. Kemampuan akademik kedua subjek juga masih tergolong rendah terutama pada pembelajaran identifikasi.

b. Memiliki masalah dalam kesehatan. 


\title{
JPK (J urnal Pendidikan Khusus), 15 (1), 2019 - 64
}

\author{
Dhea Ellyne Theodora, Aini Mahabbati
}

AGS memang mengkonsumsi obat penenang dan obat anti kejang-kejang sehingga diduga dapat mempengaruhi kondisi fisiologi subjek yang menyebabkan munculnya perilaku menyakiti diri pada subjek.

\section{Motif Perilaku Menyakiti Diri}

McCorkle (2011: 3-4) menuliskan terdapat empat motif dilakukannya perilaku menyakiti diri pada individu, yaitu mendapatkan perhatian, melarikan diri, ingin mendapatkan sesuatu, dan stimulasi diri atau sensori. Sejalan dengan McCorkle (2011: 3-4), didapatkan hasil penelitian bahwa subjek NKW melakukan perilaku menyakiti diri dengan motif sensory atau stimulasi diri dan escape atau penghindaran dari kegiatan atau benda. Sensory merupakan perasaan sensasi menyenangkan pada indera. Motif perilaku escape merupakan sebuah motif dimana subjek melakukan perilaku menyakiti diri agar ia terhindar dari tugas atau sebuah kegiatan yang tidak disukainya

Hasil penelitian pada AGS yaitu melakukan perilaku menyakiti diri dengan motif escape atau penghindaran dari suatu kegiatan atau benda dan attention atau ingin mendapatkan perhatian dari orang lain. Escape pada AGS berupa menghindari melakukan pembelajaran mengenal konsep. Motif attention terbukti pada saat semua orang di ruangan berbincang masing-masing hingga menimbulkan suara yang gaduh, AGS akan melakukan perilaku menyakiti diri karena ia menginginkan suara ocehan atau membeonya di dengarkan oleh orang-orang di sekitarnya.

\section{Pengaruh Masa Pubertas}

Kedua subjek penelitian memiliki persamaan waktu awal muncul perilaku menyakiti diri, yaitu dimulai saat memasuki masa pubertas. Bentuk perilaku menyakiti diri ini merupakan salah satu bentuk perilaku tantrum pada anak. Perilaku tantrum dapat terjadi tidak hanya pada anak usia pra-sekolah saja, namun perilaku tantrum dapat kembali muncul saat anak memasuki usia remaja atau mengalami masa pubertas. Reaksi kemarahan pada remaja tidak berbeda jauh dengan reaksi kemarahan pada anak-anak namun karena remaja merupakan masa transisi antara anak-anak menjadi lebih dewasa maka pada masa ini remaja seringkali menghadapi konflik baik konflik dalam diri sendiri maupun konflik dengan lingkungan seperti orangtua, sekolah dan teman-temannya. Pada anak autis, konflik yang dihadapi saat remaja lebih pelik lagi karena anak autis biasanya seorang yang penyendiri dan banyak diantara mereka yang memiliki hambatan dalam mengkomunikasikan perasaan dan pikirannya tanpa bantuan khusus.

Usia pubertas pada anak autis menyebabkan mereka menjadi sensitif terhadap suara, sentuhan, bau atau suatu pemandangan tertentu yang bagi orang lain mungkin biasa-biasa saja. Kondisi lingkungan yang sensitif tersebut dapat memunculkan perilaku bermasalah pada anak autis. Sehingga, dapat diketahui bahwa perilaku menyakiti diri pada subjek NKW dan AGS muncul salah satunya dipengaruhi oleh faktor masa pubertas yang sedang dialaminya. Faktor masa pubertas tersebut membuat NKW dan AGS menjadi lebih sensitif terhadap lingkungan sekitar dan cara mengkomunikasikan emosi yang dirasakan pada kedua subjek adalah dengan berperilaku menyakiti diri.

\section{Rancangan Intervensi Perilaku Menyakiti Diri}

Perilaku bermasalah dapat diperbaiki dengan mengajarkan anak perilaku target berdasarkan deskripsi lengkap pola perilaku bermasalah, menerapkan strategi antecedent dan strategi consequence. (Loman \& Borgmeier, 2015: 77). Adapun rancangan intervensi yang dapat di rekomendasikan berdasarkan hasil asesmen perilaku fungsional adalah sebagai berikut :

Tabel 5. Rancangan Intervensi Subjek NKW

\begin{tabular}{|c|c|c|}
\hline Strategi Antecedent & Perilaku yang Diinginkan & Strategi Consequence \\
\hline $\begin{array}{l}\text { Menjauhkan NKW dari objek yang ditakuti. } \\
\text { Memberikan interaksi yang menyenangkan } \\
\text { (tidak menggoda atau menakut-nakuti). } \\
\text { Menajemen lingkungan kelas yang kondusif, } \\
\text { meliputi penataan ruang kelas, pembagian } \\
\text { jumlah siswa dalam satu ruang, menciptakan } \\
\text { ruang kelas yang nyaman (pemasangan kipas } \\
\text { angin atau AC). } \\
\text { Manajemen pembelajaran yang efektif, meliputi } \\
\text { metode pembelajaran yang tepat, media } \\
\text { pembelajaran yang menyenangkan, } \\
\text { perencanaan yang preventif, dan model } \\
\text { pembelajaran kolaboratif. }\end{array}$ & $\begin{array}{l}\text { Berkurangnya perilaku } \\
\text { menyakiti diri dalam semua } \\
\text { bentuk yang sering } \\
\text { dilakukan NKW. } \\
\text { Keterampilan komunikasi } \\
\text { ekspresif. } \\
\text { Keterampilan manajemen } \\
\text { diri dalam pembelajaran. }\end{array}$ & $\begin{array}{l}\text { Menerapkan penawaran kesepakatan } \\
\text { atas perilaku negatif dan positif yang } \\
\text { dilakukan anak (contract behavior) } \\
\text { secara konsisten. } \\
\text { Perkuat ketidakmunculan perilaku } \\
\text { menyakiti diri dengan pemberian } \\
\text { penguat. } \\
\text { Memperkuat perilaku yang diinginkan } \\
\text { dengan reinforcement positive berupa } \\
\text { menonton video upin ipin atau pujian. } \\
\text { Hand cross atau menyilangkan kedua } \\
\text { tangan subjek kedepan atau kebelakang } \\
\text { agar tidak dapat menggunakan kedua }\end{array}$ \\
\hline
\end{tabular}


Tabel 6. Rancangan Intervensi Subjek AGS

\begin{tabular}{|c|c|c|}
\hline Strategi Antecedent & Perilaku yang Diinginkan & $\begin{array}{c}\text { Strategi Consequence } \\
\end{array}$ \\
\hline $\begin{array}{l}\text { Menajemen lingkungan kelas yang } \\
\text { kondusif, meliputi penataan ruang } \\
\text { kelas, pembagian jumlah siswa dalam } \\
\text { satu ruang, menciptakan ruang kelas } \\
\text { yang nyaman (pemasangan kipas angin } \\
\text { atau AC). } \\
\text { Manajemen pembelajaran yang efektif, } \\
\text { meliputi metode pembelajaran yang } \\
\text { tepat, media pembelajaran yang } \\
\text { menyenangkan, perencanaan yang } \\
\text { preventif, dan model pembelajaran } \\
\text { kolaboratif. } \\
\text { Penggantian wadah tempat makan } \\
\text { tanpa menggunakan kotak makan } \\
\text { (dapat menggunakan plastik, kertas } \\
\text { minyak, dan lain-lain). } \\
\text { Bekal makan diletakkan terpisah } \\
\text { dengan tas AGS dan langsung } \\
\text { dititipkan pada guru agar AGS tidak } \\
\text { melihat. }\end{array}$ & $\begin{array}{l}\text { Berkurangnya frekuensi dan } \\
\text { intensitas perilaku menyakiti diri } \\
\text { memukul kapala dengan sangat keras } \\
\text { pada AGS. } \\
\text { Keterampilan komunikasi ekspresif. } \\
\text { Keterampilan manajemen diri dalam } \\
\text { pembelajaran. }\end{array}$ & $\begin{array}{l}\text { Hand cross atau menyilangkan kedua } \\
\text { tangan subjek kedepan atau } \\
\text { kebelakang agar tidak dapat } \\
\text { menggunakan kedua tangan untuk } \\
\text { memukul kepala. } \\
\text { Menerapkan penawaran kesepakatan } \\
\text { atas perilaku negatif yang dilakukan } \\
\text { anak (contract behavior) secara } \\
\text { konsisten. } \\
\text { Menerapkan time out saat perilaku } \\
\text { muncul, dengan memindahkan subjek } \\
\text { pada ruang khusus yang sepi. } \\
\text { Mengabaikan perilaku menyakiti diri } \\
\text { yang dilakukan AGS secara konsisten } \\
\text { dan melibatkan seluruh anggota } \\
\text { kelas/kelompok (untuk ikut } \\
\text { mengabaikan). }\end{array}$ \\
\hline
\end{tabular}

\section{SIMPULAN}

\section{Simpulan}

Berdasarkan hasil penelitian diambil kesimpulan sebagai berikut:

1. Pola Perilaku Menyakiti Diri

a. Subjek NKW

Bentuk perilaku menyakiti diri pada subjek NKW berupa: 1) memukul kepala; 2) membenturkan kepala pada meja; 3) membenturkan kaki pada lantai; 4) menyayat kulit di sekitar kuku jari tangan. Bentuk perilaku tersebut muncul saat terdapat pemicu atau anteseden berupa: 1) diganggu oleh orang lain; 2) melihat buah salak; 3) panas; 4) melihat benda tidak sesuai pada tempatnya; 5) penundaan dan pembatalan suatu rutinitas; 6) guru menyatakan anak salah menjawab atau melakukan tugas. Hal yang didapatkan NKW setelah terjadinya perilaku menyakiti diri adalah: 1) mendapatkan rasa sensasi atau sensori; 2) terhindar dari sebuah tugas maupun kegiatan. Faktor yang dapat mempengaruhi perilaku subjek NKW berupa kemampuan komunikasi ekspresi yang rendah.

b. Subjek AGS

Bentuk perilaku menyakiti diri pada subjek AGS berupa: a) memukul kepala menggunakan tangan dengan keras; b) memukul meja (gebrakan pada meja). Bentuk perilaku tersebut muncul saat terdapat pemicu atau anteseden berupa: 1) melakukan dan mendengar pembelajaran identifikasi; 2) melihat makanan diletakkan di kotak makan; 3) kebisingan verbal pada ruangan. Hal yang didapatkan AGS setelah terjadinya perilaku menyakiti diri adalah: 1) terhindar dari sebuah tugas maupun kegiatan; 2) mendapatkan perhatian dari orang lain. Faktor yang mempengaruhi perilaku AGS berupa kemampuan komunikasi ekspresi yang rendah, pengkonsumsian obat penenang dan anti kejang, dan pola tidur yang kurang teratur.

\section{Saran}

Berdasarkan hasil penelitian dan simpulan, peneliti memberikan saran yaitu:

1. Bagi guru

a. Sebaiknya guru kelas segera melaksanakan asesmen perilaku bermasalah saat mendapati siswanya memiliki perilaku bermasalah. Hal ini bertujuan agar siswa mendapatkan intervensi lebih dini dan perilaku bermasalahnya tidak berangsur-angsur menjadi semakin berat karena tidak tertangani.

b. Faktor kepekaan guru dalam memahami sinyal komunikasi yang diberikan oleh anak perlu ditingkatkan. Siswa yang memiliki hambatan dalam komunikasi, akan mencari hal lain agar orang terdekatnya dapat mengetahui. Namun apabila guru tidak menangkap sinyal tersebut atau tidak 


\section{JPK (J urnal Pendidikan Khusus), 15 (1), 2019 - 66}

Dhea Ellyne Theodora, Aini Mahabbati

memahami, hal yang mungkin terjadi adalah siswa marah dan menunjukkan dengan berperilaku menyakiri diri.

2. Bagi orang tua

a. Sebaiknya orang tua melakukan konsultasi sedini mungkin terhadap guru, psikolog atau psikiater saat menemukan perilaku menyakiti diri pada anak.

b. Menjalin hubungan yang kompak dengan guru kelas, agar anak mendapatkan penanganan yang berkelanjutan saat di rumah dan di sekolah sehingga dapat membentuk sikap dan kepribadian anak menjadi lebih baik.

3. Bagi peneliti selanjutnya, sebaiknya penelitian dilakukan untuk menerapkan atau pelaksanaan sebuah rancangan intervensi agar dapat mengurangi perilaku menyakiti diri pada subjek berdasarkan hasil asesmen yang sudah ditulis dalam penelitian ini.

\section{DAFTAR PUSTAKA}

Alsa, A. (2007). Pendekatan Penelitian Kualitatif \& Kuantitatif serta Kombinasinya dalam Penelitian Psikologi. Yogyakarta: Pustaka Belajar.

Arifin, Z. (2011). Penelitian Pendidikan. Bandung: PT Remaja Rosdakarya.

Association, A. P. (2013). Diagnostic And Statistical Manual of Mental Disorder Edition "DSM-5". Washinton DC: American Psychiatric Publishing.

Azwandi, Y. (2005). Mengenal dan Membantu Penyandang Autisme. Jakarta: Departemen Pendidikan Nasional.

Buck, T. (2017). Aggression and self injurious behaviors: the effects of behavior interventions in young adults with autism spectrum disorder. Rowan: Theses and Dissertations. 2477. Rowan University Rowan Digital Works.

Conterio, K., \& Lader, W. (2014). Self-Injurious Behaviors. Diakses pada 30 Januari 2019, dari Mental Health America of Illinois (MHAI): http://www.mhai.org

Danuatmaja, B. (2003). Terapi Anak Autis di Rumah. Jakarta: Puspa Swara.

Durand, V., \& Crimmins , D. (1988). Identifying the Variables Maintaining Self-Injurious Behavior. Journal of Autism and Developmental Disorders, Vol. 18, No. 1(Vol. 18, No. 1).

Emzir. (2011). Metodologi Penelitian Kualitatif : Analisis Data. Jakarta: PT. RajaGrafindo Persada.

Excellence, N. I. (2004). Autism in Children, Young People and Adults.

Freeman, R. (n.d.). Functional Behavioral Assessment. Diakses pada 29 Januari 2019, dari University of Kansa: http://www.specialconnections.ku.edu

Gresham, F., Watson, T., \& Skinner, C. (2001). Functional Behavioral Assessment: Principles, Procedures, and Future Directions. School Psychology Review. 30.2 (Spring 2001): p156., Volume 30(No. 2), 156-172.

Gurney, E., \& Iseri, E. (2013). Genetic and Environmental Factors in Autism. 321-339.

Hadaway, S., \& Brue, A. (2016). Practitioner's Guide to Functional Behavioral Assessment, Autism and Child Psychopathology Series. Springer International Publishing Switzerland, 9-21.

Hallahan, D., Kauffman, J., \& Pullen, P. (2009). Exceptional Learners: an Introduction to Special Education (11th ed). United States of America: Pearson International Edition.

Iskandar. (2009). Metodologi Penelitian Kualitatif. Jakarta: Gaung Persada (GP Press).

Loman, S., \& Borgmeier, C. (2015). Practical FBA Participant's Guide. Portland: Portland State University.

Love, J., Carr, J., \& Leblanc, L. (2009). Functional Assessment of Problem Behavior in Children with Autism Spectrum Disorders: A Summary of 32 Outpatient Cases. J Autism Dev Disord, 39: 363-372.

McCorkle, S., \& College, L. (2011). Decreasing Self-Injurious Behaviors in Children with Autism Spectrum Disorders. Decreasing Self-Injurious Behaviors In Children With Asd, 1-15.

Midlands, A. W. (2016). Autism and Menyakiti diri. Diakses pada 28 Januari 2019, dari http://www.autismwestmidlands.org.uk

Miles, M., \& Huberman, A. (1992). Analisis Data Kualitatif. (T. R. Rohidi, Trans.) Jakarta: UI Press.

Miltenberger, R. (2009). Behavior Modification: Principle and Procedures. Canada: PreMedia Global.

Minshawi, N., Hurwitz, S., Fodstad, J., Biebl, S., Morriss, D., \& McDoughle, C. (2014). The association between self-injurious behaviors and autism spectrum disorders. Psychology Research Behavioral Management, 125-136. 
Moedzakir, D. (2010). Desain dan model penelitian kualitatif. Malang: FIP UNM.

Moleong, L. J. (2009). Metodologi Penelitian Kualitatif. Bandung: PT. Remaja Rosdakarya Offset.

Muwakhidah. 2014. Functional Behavior Assessment. Surabaya: UNIPA Surabaya

Neitzel, J., \& Bogin, J. (2008). Steps for Implementation: Functional Behavior Assessment. Chapel Hill, NC: The National Professional Development Center on Autism Spectrum Disorders, Frank Porter Graham Child Development Institute, The University of North Carolina.

Pamuji. (2007). Model Terapi Terpadu Bagi Anak Autisme. Jakarta: Departemen Pendidikan Nasional. Philadelphia, T. C. (2014). Self Injurious Behavior. UK, Philadelphia.

Ravensberg, H., \& Blakely, A. (2015). When to use Functional Behavioral Assessment?A State-byState Analysis of the Law. Diakses pada Januari 26, 2019, from OSEP Technical Assistance Center on Positive Behavioral Interventions and Supports: www.pbis.org.

Richards, C., Davies, L., \& Oliver, C. (2017). Predictors of Self-Injurious Behavior and SelfRestraint in Autism Spectrum Disorder: Towards a Hypothesis of Impaired Behavioral. Journal of Autism and Developmental Disorders, 1-13.

Sastry, A., \& Aguirre, B. (2014). Parenting Anak dengan Autisme. Yogyakarta: Pustaka Pelajar.

Shippen, M., Simpson, R., \& Crites, S. (2003). A Practical guide to Functional Behavior Assessment. Teaching Exceptional Children, 37.

Soares, D. V. (2009). Computer aided self-monitoring to increase academic production and reduce self-injurious behavior in a child with autism. Behavioral Interventions, 171-183.

Soke, G. N., Rosenberg, S. A., Rosenberg, C. R., Vasa, R., Lee, L.-C., \& DiGuiseppi, C. (2018, Juli). Self-injurious behaviors in children with autism spectrum disorder enrolled in the Study to Explore Early Development. 1-20.

Stage, S. A. (2000). The Validity Functional Behavior Assessment with Student of Average Intellectual Ability. Canadian Journal of School Psychology, Volume 15, Number 2, 67-84.

Sugai, G., Palmer, T. L., \& Burke, S. H. (2000). Overview of the Functional Behavioral Assessment Process. EXCEPTIONALITY , 8 (3), 149-160.

Sugiyono. (2017). Metode Peelitian Kuantitatif, Kualitatif, dan R\&D. Bandung: ALFABETA.

Sukardi. (2011). Metodologi Pemenelitian Pendidikan: Kompetensi dan Praktiknya. Jakarta: Bumi Aksara.

Suteja, J. (2014, Januari-Juni ). Bentuk dan Metode Terapi Terhadap Anak Autisme Akibat Bentukan Sosial. Jurnal Edueksos, Vol III No 1, 119-133.

Waguespack, A., Vaccaro, T., \& Conti, L. (2006). Functional behavior Assessment and Intervention withEmotional/Behaviorally Disordered Students: In Pursuit of State of the Art. International Journal of Behavioral Consultation and Therapy, Volume 2, No. 4, 463-474. 